\title{
IMITAÇÃO DE RETÓRICAS LATINAS NA CONCEPÇÃO DE GÊNEROS E ESTILOS DA MUSICA POETICA
}

\author{
Mônica Lucas* \\ Depto. de Música - ECA- \\ USP \\ monicalucas@usp.br
}

RESUMO: A vinculação entre a música e as artes do trivium remonta a uma tradição antiga. Contudo, foi na pena de escritores luteranos do início do século XVII que a música e a palavra se aproximaram de maneira sistemática, de modo que a primeira passou a ser entendida como arte persuasiva, sujeita a regras gramáticas e retóricas. A transferência destes preceitos verbais para a composição musical se deu de maneira cada vez mais intensa a partir do século XVI, perdurando até o fim do séc. XVIII. Essas transposições formaram a base da teoria de composição musical conhecida no mundo luterano como musica poetica.

Neste artigo, concentrar-nos-emos na teoria retórica dos gêneros e estilos musicais, como compreendida em preceptivas seiscentistas e setecentistas. Mostraremos como a musica poetica foi se aproximando dos ideais retóricos humanistas e como esta aproximação colaborou para consolidar a ideia de música como linguagem, no final do séc. XVIII.

PALAVRAS-CHAVE: Retórica musical - Musica poética - Estilo - Gênero

\section{TITLE: IMITATION OF LATIN RHETORIC TEXT- BOOKS IN MUSICA POETICA'S GENDER AND STYLE CONCEPTION}

ABSTRACT: The link between music and the arts of trivium
can be traced back to an old tradition. However, music and
word only approximated in a more systematic way in the writ-
ings of Lutheran theorists. Music came to be understood as
a persuasive art, subject to grammatical and rhetorical rules.
The transfer of these verbal principles to music composition
happened in an ever more intense way between the $16^{\text {th }}$ and 
the $18^{\text {th }}$ Centuries. These transpositions formed the basis of a musical composition theory known in the Lutheran world as musica poetica.

In this article, I concentrate in the musical-rhetoric gender and style theory, as understood in $17^{\text {th }}$ and $18^{\text {th }}$ Century textbooks. This will show how musica poetica came closer to rhetorical humanist ideals, and how this approximation helped to consolidate the idea of music as a language in the end of the $18^{\text {th }}$ Century.

KEYWORDS, Musical Rhetoric - Musica Poetica - Style Gender

A vinculação entre a música e as artes do trivium remonta a uma tradição antiga, embora, durante toda a Idade Média, a música tenha sido considerada como arte pertencente ao quadrivium. No ocidente, teóricos medievais, ao discorrer sobre as regras da composição, já utilizam termos emprestados da gramática: cláusula, ponto, vírgula. No século X, algumas estruturas musicais, como os tropos e seqüências, são construídas levando em conta a simetria dos versos e das rimas presentes no texto. A partir do século XI, os esquemas formais da poesia trovadoresca passam a ser amplamente utilizados como elementos de construção musical. Assim, denominaçóes como lai, rondeau, virelai, balada, passam a indicar não apenas estruturas poéticas, mas também formas musicais.

Contudo, foi na pena de escritores luteranos do início do século XVII que a música e a palavra se aproximaram de maneira sistemática, de modo que a primeira passou a ser entendida como arte instrutiva, deleitável e comovente, sujeita a regras gramáticas e retóricas. Nesse processo, obras antigas revalorizadas durante o humanismo, em especial a Retórica aristotélica, o De Oratore de Cícero e a Institutio Oratoria de Quintiliano passaram a ser entendidas como fontes normativas também para a composição e a interpretação musicais.

A transposição de conceitos gramáticos e retóricos para a composição musical se deu de maneira cada vez mais intensa a partir do século XVI. Essas transposições formaram a base da teoria de composição musical conhecida no mundo luterano como musica poetica. 
As poéticas musicais quinhentistas e seiscentistas são preceptivas práticas, para uso nas escolas latinas no mundo reformado. O que diferencia obras como o De Musica de Nikolaus Listenius (1537) ou o Musica Poetica, de Joachim Burmeister (1606) de outras obras práticas amplamente utilizadas por alunos dessas escolas pré-universitárias no séc. XVI não é tanto a matéria (solfejo e estudo do contraponto), mas a maneira de caracterizar procedimentos musicais. Listenius acrescenta à divisão medieval de música theorica e practica, uma terceira classe, poetica, fazendo clara referência às poéticas antigas. Burmeister emprega termos novos, emprestados da retórica, para discorrer sobre a invenção, elocução e disposição musicais.

Em 1732, Johann Mattheson publica Der Vollkommene Capellmeister ["o mestre-de-capela perfeito"], o mais extenso e completo compêndio sobre a retórica musical. A obra se distingue em diversos aspectos de suas antecessoras: não se destina ao público escolar, mas o galant-homme frequentador dos círculos cortesãos, e, além disso, é escrita em alemão, e não em latim. Mattheson apresenta uma visão abrangente da sistemática musical gramática e retórica, incluindo todos os estágios da produção do discurso musical. Ele também discorre sobre as virtudes do mestre-de-capela e centra suas discussões na ideia de decoro, apresentando discussões que não acontecem em poéticas musicais anteriores. A proximidade com retóricas latinas recém-descobertas no séc. XV, em especial obras de Cícero e Quintiliano, já se inicia pelo título, que remete diretamente ao ideal do orador perfeito proposto por estes autores.

No fim do séc. XVIII, Johann Nikolaus Forkel faz uma descrição completa da linguagem musical, em termos de gramática e retórica. A poética de Forkel apresenta uma visão muito benevolente a respeito da música instrumental, o que não ocorre em obras anteriores. Forkel é um dos últimos autores a se inserir na tradição da musica poetica.

Neste artigo, concentrar-nos-emos na teoria retórica dos gêneros e estilos musicais, como compreendida em preceptivas seiscentistas e setecentistas. Com isto, mostraremos como a musica poetica foi se aproximando dos ideais retóricos humanistas e como esta aproximação colaborou para consolidar a ideia de música como linguagem. 


\subsection{GÊNEROS E ESTILOS MUSICAIS}

O termo retórico estilo vem do latim stilus, o ferro pontiagudo com que se escrevia nas tábuas enceradas, e, por extensão, refere-se, já em Cícero, à maneira de escrita. Johann Mattheson, em seu referencial Der Vollkommene Capellmeister, reproduz um enunciado de Sébastien de Brossard (1701), e define estilo como a maneira como uma pessoa compóe, executa e se comunica. Forkel completa a definição, dizendo que esta maneira deve se ajustar a intençōes e usos determinados, ou seja, deve levar em conta a ocasião e o público. Para este último, os estilos musicais são formas de escrita que se distinguem por sua forma, por sua essência e por sua destinação.

$\mathrm{O}$ conceito de estilo foi incorporado ao vocabulário musical no início do século XVII, fixando-se em tratados seiscentistas e setecentistas. Não existe uma vinculação assumida, por parte destes autores, entre os gêneros e estilos musicais e aqueles prescritos pelas retóricas latinas, mas há semelhanças que deixam clara esta ligação, como observaremos a seguir.

Por estilos e gêneros, teóricos musicais seiscentistas e setecentistas entendem as seguintes classificações:

1. segundo os gêneros melódicos (diatônico, cromático, harmônico) e estilos de

contraponto (simplex, fractum, coloratum);

2. segundo a técnica de composição: estilo antigo ou moderno;

3. segundo o temperamento de um grupo (nação, povo): estilo francês, italiano ou

alemão;

4. segundo a circunstância de representação: estilo teatral, de câmara ou sacro

5. segundo a qualidade da matéria: alto, médio, baixo

6. segundo os subgêneros musicais (derivada das três anteriores)

As diversas classificações propostas não são excludentes entre si. Contudo, o que orienta cada uma delas é um enfoque distinto das características internas e/ou funçôes das espécies que as compõem. 
A primeira categoria, que constitui a divisão mais antiga, leva em conta apenas elementos internos da composição. Joachim Burmeister, em seu Musica Poetica (1606) considera os gêneros musicais sob dois aspectos: o primeiro trata dos gêneros melódicos [genus carminibus sive modulaminum], que constituem os modos diatônico, cromático e harmônico. $\mathrm{O}$ segundo se refere aos tipos de contraponto [genus antiphonum alias dictum contrapunctus], e descreve as espécies simplex (com notas brancas), fracta (contraponto em que aparecem algumas notas coloridas [pretas]) e colorata (contraponto colorido, em que predominam as notas coloridas [pretas]).

A segunda divisão também se fundamenta em elementos puramente musicais. Ela já aparece na famosa controvérsia entre os irmãos Claudio e Giulio Cesare Monteverdi versus Giovanni Artusi, por ocasião da publicação do $5^{\circ}$ Livro de Madrigais de Claudio Monteverdi (1605). Ao defender estas composiçōes, os irmãos lançam mão da oposição entre os estilos que denominam de antigo (prima prattica) e novo (seconda prattica). O estilo novo sancionaria o uso de liberdades composicionais criticadas por Artusi. É interessante notar que, nesse estilo, essas liberdades permitem explorar ao máximo o conteúdo afetivo do texto. Em outras palavras, nesta chave de organização, é o texto - ou melhor, o conceito por ele representado - que regula certos procedimentos musicais.

A oposição entre os estilos antigo e novo é retomada por Marco Scacchi, que, em seu Breve Discorso sopra la Musica Moderna (1649), afirma que

o estilo antigo consiste em uma prática e quase que em um e no mesmo estilo de empregar consonâncias e dissonâncias. (...) As práticas são: na primeira, [a prática antiga], é Ut Harmonia sit Domina Orationis [como se a harmonia fosse senhora do discurso]; na segunda, [o estilo moderno], é ut Oratio sit Domina Harmoniae [como se o discurso fosse senhor da harmonia]. Cada um desses três estilos contém grandes variaçōes, novidades e invençôes de extraordinária dimensão. ${ }^{1}$ (Scacchi, 1994 [1649], p. 110)

Christoph Bernhard, aluno de Heinrich Schütz em Dresden e colega de Scacchi em Varsóvia, baseia-se claramente na divisão deste último, e a amplia: em seu Tractatus Compositionis Augmentatus (c. 1657), ele opõe o stylus gravis (antiquus, ecclesiasticus) ao stylus modernus (luxurians,
1. "La Musica antica consiste in una prattica sola, e quasi in un medesimo stile, diadoperare le consonanze, e dissonanze; (...). Le prattiche sono: la prima è, Ut Harmonia sit Domina orationis; la seconda, ut Oratio sit Domina harmoniae; et in ogn'uno di questi tre stili portano in se grandissime arazioni, novità, et invenzioni di non ordinaria considerazioni”. 
theatralis), que se subdivide novamente em communis e comicus (recitativus, oratorius). Ele afirma que, no estilo antigo, "a harmonia predomina sobre o discurso" [harmonia orationis domina], enquanto no stylus communis, há igual predominância entre palavra e harmonia; finalmente, no stylus comicus, "o discurso é senhor absolutíssimo da harmonia" [oratio harmoniae domina absolutissima]. (apud. Dammann, 1995, p. 106 )

Nos escritos de Scacchi e Bernhard fica claramente perceptível uma preocupação com a união entre música e linguagem, que não ocorreria, segundo esses autores, na música de estilo antigo. Quase um século após, esta divisão, já totalmente consolidada na tratadística musical, é reapresentada por Mattheson (1739), na forma dos estilos ligado e livre. Passa, ainda, a ser comumente descrita em tratados de contraponto do século XVIII, como Der Kunst des reinen Satzes in der Musik ["a arte da composição correta na música”] (1771-1779), de Johann Kirnberger, com os termos estrito e galante (Kirnberger, 1987, p. 189).

Forkel (1784) também divide os estilos nas categorias monódico e polifônico. Contudo, esta divisão o leva a conclusóes distintas de Scacchi e Bernhard. Para ele, a monodia representa as emoções de um indivíduo único, com todas suas variações, enquanto a polifonia representa as emoções coletivas de um grupo de pessoas. Por esta razão, a polifonia é superior à monodia.

Forkel considera a fuga, dentre todos os gêneros, o mais elevado. Sempre se fundamentando na analogia entre música e linguagem, ele afirma que esta superioridade se dá pelo fato de a fuga consistir a expressão das emoções de um povo inteiro:

Imaginemos um povo, que, pela narração de um acontecimento importante, seja colocado em um estado emotivo; imaginemos em seguida, que um integrante (...) seja compelido à expressão desta emoção, e manifeste seu sentimento com uma frase curta e forte. Esse rompante emocional não tomaria paulatinamente todos os membros desse povo? Não o seguiriam inicialmente algumas pessoas, depois mais e, por último, a maioria? E não se conformariam todos a esse canto, modificando-o não de acordo com sua emoção individual, mas em concordância com o sentimento principal? E se uma apresentação, um rompante de emoção, deve ser representado musicalmente, não parece a coisa mais natural do mundo [aparecer] primeiramente o guia (dux) e em seguida o companheiro (comes) e a repetição (repercus- 
sio) - em suma, [aparecer] toda uma forma interna e externa da fuga? (...) Não é essa utilização artificiosa e variada um retrato fiel da natureza, não é ela a expressão mais perfeita das emoçôes variadas e modificadas das emoçôes de todos os membros de um povo, que surgem paulatinamente, e se espalham para todos em uma corrente comum? ${ }^{2}$ (2005 [1784], \$93).

No percurso de tempo de pouco mais de um século, decorrido entre os escritos de Scacchi e Forkel, é possível observar uma enorme ampliação do conceito de retórica musical. Para o primeiro, no contraponto predominam os procedimentos matemáticos, de modo que a palavra fica subordinada à música; para o segundo, a música constitui sempre uma expressão de emoções, mesmo que o estilo utilizado seja o do contraponto. Esta ampliação permite a Forkel uma valorização da música instrumental, que não é possível em Scacchi.

$\mathrm{O}$ terceiro tipo de divisão se refere à distinção entre os estilos que Athanasius Kircher (1650) e, posteriormente, vários autores que o repetem, como Thomas Janowka (1701) e Johann Gottfried Walther (1732), denominam impressus e expressus $\mathrm{O}$ estilo impresso resulta de um temperamento natural, que inclina cada indivíduo a seguir um tipo ou outro de melodia, seguindo a diversidade das nações. Kircher menciona como modelos principais o estilo alemão (grave, firme, constante e polifônico), o francês (vivaz e o mais adequado à dança) e italiano (o mais musical, por constituir um meio termo, não sendo nem tão afeito à dança nem excessivamente sério). No séc. XVIII, são estes os três principais modelos nacionais, como bem demonstrou Paoliello (2011, p. 72-108). ${ }^{3}$ $\mathrm{O}$ estilo expressus refere-se à manifestação destas preferências nos subgêneros musicais.

Nos debates envolvendo a oratória romana, também se discute a imitação de modelos a partir da inclinação natural de cada autor. Novamente, retóricas antigas referenciais para o humanismo - em especial o De Oratore e a Institutio Oratoria - são a principal fonte para esta discussão, que também é retomada por oradores seiscentistas, como Emanuele Tesauro. Cícero pressupooe o aprendizado da retórica a partir do processo de imitação de autores exemplares. Este processo, que ensina a dominar estilos diversos, é adotado para o estudo do grego e do latim nas escolas do mundo reformado. Para Cícero, os principais estilos da oratória são o ático e o asiático,
1. "La Musica antica consiste in una prattica sola, e quasi in un medesimo stile, diadoperare le consonanze, e dissonanze; (...). Le prattiche sono: la prima è, Ut Harmonia sit Domina orationis; la seconda, ut Oratio sit Domina harmoniae; et in ogn'uno di questi tre stili portano in se grandissime varazioni, novità, et invenzioni di non ordinaria considerazioni”".

2. "Man stellet sich also ein Volk vor, welches durch die Erzählung einer wichtigen Begebenheit in Empfindung gesetzt worden ist, und denke sich nun, dass ein Mitglied desselben, vielleicht durch die Stärke seiner Empfindung zur Aeusserung derselben zuerst hingegriffen, einen kurzen kräftigen Satz als Ausdruck seines Gefühls anstimmt; wird nicht dieser Ausbruch seiner Empfindung nach und nach die sämmtlichen Glieder dieses Volks ergreifen, wird ihm nicht erst eines, dann mehrere, und zuletzt die meisten nachfolgen, und jedes den angestimmten Gesang, zwar nach seiner eigenen individuellen Empfindungsart modificiren, im Ganzen oder dem Hauptgefühl nach mit ihm

überstimmen? Und wenn ein solcher Auftritt, eine solche nach und nach ausbrechende Aeusserung der Empfindung musikalisch geschildert werden soll, entsteht nicht auf das natürlichsten von der Welt, erstlich der

Führer $(d u x)$, sodan der Gefahrte (comes), der 
Wiederschlag (repercussio), kurz, die ganze äussere und innere Form der

Fuge? (...) ist nicht diese mannichfaltige und künstliche Bewebung, eine getreue Abbildung der Natur, ist sie nicht der vollkommenste Ausdruck der mannichfaltig modificirten Empfindungen aller Glieder eines Volks, die erst nach und nach entstehen, sodann aber in einen allgemeinen Strom sich ergiessen?".

4. "primum igitur assero, triplicem omnino stylum in arte musices reperiri: ecclesisasticum, cubicularem \& scenicum seu theatralem, quorum singul diversis etia modis a peritis considerari oportet \&c...”.

5. cf. Quintiliano. Institutio Oratoria. III, 3-4; Anônimo. Retórica a Herênio. I, 2, 2 representados, respectivamente, pelo historiador Menecles e pelo orador Ésquines. Considerando a importância de Cícero nas leituras cortesãs e escolares do humanismo, é possível enxergar a concepção de estilo impresso ou expresso como uma transposição musical de questôes retóricas envolvendo a imitação de autoridades.

A quarta classificação também aparece em Monteverdi, no prefácio do $8^{\circ}$ Livro de Madrigais (1638), quando ele afirma que os três estilos de madrigais contidos naquela coleção - guerreiros, amorosos e representativos - correspondem aos estilos de música teatral, de câmara e de dança, e requerem, por sua vez, três tipos correspondentes de interpretação: oratória, harmônica e rítmica (Monteverdi, 1990 [1638], p. ii].

Cerca de uma década após Monteverdi, Marco Scacchi altera este esquema, transformando-o, segundo Palisca, na principal divisão utilizada por autores da musica poetica, entre eles Johann Mattheson e Johann Nikolaus Forkel. Para ele, diferentes ocasiōes de interpretação determinam os estilos sacro [ecclesiasticus], de câmara [cubicularis] e teatral [theatralis]. Scacchi diz que "o [estilo] moderno é composto de duas práticas e três estilos, a saber, o estilo de igreja, o de câmara e o teatral" ([1649] ,1994 p. 110).

Mattheson menciona Scacchi diretamente em seu Der Vollkommene Capellmeister, e reitera as ideias deste: "afirmo, portanto, em primeiro lugar, encontrarmos três estilos na arte musical: eclesiástico, de câmara e cênico ou teatral, que devem ser considerados pelos conhecedores de maneiras diversas." (Mattheson, 1991 [1739]). ${ }^{4}$ Obras de Scacchi talvez tenham estado disponíveis para Mattheson no período em que este último foi aluno da escola latina do Johanneum. Johannes Gerstenbüttel, professor de música daquela escola, fora aluno de Christoph Bernhard, que, por sua vez, havia sido colega e seguidor de Scacchi.

A divisão de gêneros segundo a ocasião parece constituir uma transposição dos gêneros de causas (judicial, deliberativo, demonstrativo) da retórica clássica. ${ }^{5}$ Ambas divisões dizem respeito a circunstâncias de ocasião: para os gêneros retóricos, o fórum, a assembleia e a solenidade civil; para os gêneros musicais, o teatro, a igreja e a câmara.

A quinta divisão dos gêneros - segundo a matéria tratada - aparece também no escrito de 1638 de Monteverdi (o pre- 
fácio do $8^{\circ}$ livro de madrigais), quando ele se refere aos estilos agitado [concitato], temperado [temperato] e triste [molle], que devem ser empregados de acordo com os afetos principais representados na música: ira, temperança e humildade. Vale lembrar que, no prefácio do Combattimento di Tancredi e Clorinda (1624), Monteverdi afirma ser o primeiro a utilizar a ira como matéria musical.

Esses gêneros sugerem uma correspondência direta com os genera dicendi retóricos, em especial com a terminologia de Santo Agostinho. O genus humile (Agostinho) se assemelha ao molle de Monteverdi (que, segundo este último, representa a humildade); o genus temperatum (Agostinho), se aproxima do temperato (Monteverdi) e o genus grande (Agostinho), do concitato (Monteverdi).

Johann Mattheson, em seu Der Vollkommene Capellmeister, substitui as qualificações empregadas por Monteverdi pelos adjetivos ciceronianos alto, médio e baixo. Estes termos também aparecem no Versuch einer critischen Dichtkunst für die Deutschen ["ensaio sobre uma poética para os alemães"] (1730), uma arte poética de Johann Gottsched, colega que frequentava o mesmo círculo de Mattheson em Hamburgo.

Forkel também apresenta uma divisão dos estilos segundo o afeto representado. Contudo, ao invés da divisão ternária tradicional, ele propõe uma categorização quádrupla, que inclui afetos tristes, alegres, serenos e violentos. Ele próprio lembra que esta divisão não é comumente empregada.

Finalmente, com relação à sexta e última divisão, que organiza os estilos principais em subgêneros, a classificação mais antiga aparece no Musurgia Universalis, de Athanasius Kircher (1650). Nele, o jesuíta divide o estilo expresso, ou seja, os subgêneros musicais, em três categorias principais - os estilos ecclesiasticus, theatralis e um terceiro grupo misto, que inclui peças adequadas tanto à ocasião sacra quanto à teatral. $\mathrm{O}$ estilo sacro inclui os subgêneros canonicus e moteticus. No estilo teatral, inserem-se os subgêneros dramaticus e hypochermaticus. No misto, estão incluídos os estilos madrigalescus, melismaticus, symphoniacus e phantasticus.

Nesse esquema, a música instrumental está contemplada pelos estilos theatralis, na categoria hyporchematicus (que se refere às danças), e pelo grupo misto, com as categorias symphoniacus (que compreende peças polifônicas para conjunto 
instrumental) e phantasticus (que inclui todos os outros tipos de composiçóes instrumentais). Vale notar que o estilo symphoniacus consiste em uma transposição do contraponto vocal para a música instrumental, enquanto o phantasticus é o gênero instrumental por excelência.

Kircher define este estilo da seguinte maneira:

"O estilo fantástico é o método mais livre de composição; [ele é] livre de quaisquer limitações do texto ou de harmonia pré-determinada [e serve] para exibir o engenho. Foi estabelecido para revelar o sistema oculto [ratio abdita) da harmonia (...). É dividido em categorias comumente chamadas fantasias, ricercares, toccatas e sonatas" (1999 [1650], I,7,3,7).

A definição que Kircher apresenta do estilo phantasticus é bastante sucinta, em comparação com espaço que ele devota a outros gêneros. Contudo, é interessante notar que fantástico é definido como o gênero que mais se afasta da coerência construtiva do contraponto. A sonata, que se transformará na principal escrita instrumental no fim do século XVIII, é, para Kircher, um gênero fantástico.

A caracterização do estilo puramente instrumental como fantástico nos remete diretamente ao Sofista platônico. Neste diálogo, o Estrangeiro de Eleia diferencia as imagens icásticas, proporcionais ao paradigma, das fantásticas, que o deformam. As imagens fantásticas requerem correção pelo olhar do espectador. Uma transposição desta noção para o estilo fantástico de Kircher parece indicar a música eminentemente instrumental como uma espécie merecedora de uma audição específica - engenhosa -, capaz de perceber uma ordem por trás da aparente incongruência dos fragmentos musicais justapostos e pela ausência do contraponto.

Johann Mattheson edita seu Der Vollkommene Capellmeister em 1739, quase um século após Kircher. Ao tratar dos estilos musicais, ele parte da divisão de seu antecessor, mas a reelabora, acrescentando aos três estilos instrumentais descritos pelo jesuíta - hypochermaticus, symphoniacus e phantasticus - um quarto, o estilo instrumental, das peças que acompanham a ação teatral e da Tafelmusik, relacionada às celebrações festivas. Os dois gêneros instrumentais mais importantes na segunda metade do século XVIII, a sonata e o concerto, são, para Mattheson, espécies de Tafelmusik. 
Enquanto a descrição que Mattheson faz dos estilos hypochermaticus (da dança) e symphoniacus (do contraponto) permanece muito próxima da de Kircher, ele divide o estilo que o jesuíta descreve como phantasticus em dois gêneros instrumentais distintos. No primeiro, que retém a qualificação fantástico, permanecem as peças tocadas "a partir do espírito livre" e nas quais o compositor deve engenhosamente observar o "lugar adequado e o ponto correto" no qual pensamentos livres são expressos de acordo com o gosto pessoal, encadeando livremente suas idéias. Ele consiste de gêneros como a fantasia, o cappriccio, a toccata, o ricercare, etc. (1990 [1739], I, 10, 88). No segundo, que Mattheson denomina propriamente instrumental, impera a clareza de linguagem, que se contrapõe ao estilo engenhoso e obscuro das peças fantásticas (Ibid., I, 10, 74). Ao oferecer essa distinção, Mattheson, embora não chegue a atribuir à música instrumental uma importância equivalente àquela conferida à sua contrapartida vocal, admite uma coerência própria para o discurso instrumental, não dependente da palavra..

Ele reforça essa ideia em pelo menos dois pontos de seu tratado: ao descrever o estilo symphoniacus, afirma que "a música instrumental nada mais é que um discurso de sons ou linguagem de tons, e, sendo assim, sua atenção deve se dirigir inteiramente para um certo movimento de espírito" (Ibid., I, 10, 63). Em outro trecho, repete a asserção de que a música instrumental (assim como a vocal) se volta para a representação dos afetos e de que "os instrumentos, por meio do som, constituem um discurso simultaneamente eloqüente e compreensível." (Ibid., II, 4, 45). ${ }^{6}$

Apesar da visão benevolente em relação à música instrumental, autores como Mattheson não chegam a atribuir a ela uma posição equivalente à que conferem à música vocal. No entanto, abrem caminho para a concepção de música instrumental como um discurso constituído de gramática e retórica próprias, e com isso, geram espaço para uma mudança de concepção que será reforçada por autores da segunda metade do século XVIII, como Johann Christoph Koch, Johann Georg Sulzer e principalmente Johann Nikolaus Forkel.

Forkel, ao tratar dos gêneros musicais, também os distingue segundo sua destinação. Contudo, sua classificação se dá principalmente pela técnica de escrita (monodia ou polifonia)
6. "allein, man muss doch hiebey wissen, dass auch ohne Worte, in der blossen Instrumental-Music allemahl und bey einer ieden Melodie, die Absicht auf eine Vorstellung der regierenden Gemüths-Neigung gerichtet seyn müsse, so dass die Instrumente, mittelst des Klanges, gleichsam einen reddened und verständlichen Vortragmachen“". 
e pela textura (vocal ou instrumental), sem penetrar na questão a respeito da primazia da música vocal sobre a instrumental. Como Forkel mesmo afirma, estas questōes não são relevantes, uma vez que os meios técnicos não invalidam o fato de que a música, qualquer que seja, constitui uma linguagem.

Sendo assim, a classificação dos estilos musicais segundo seus subgêneros é aquela que tem maior relevância para a constituição da ideia de linguagem musical. Esta concepção permite pensar a música - independentemente da presença do texto - como uma arte gramática e retórica.

\section{CONCLUSĀo}

Ao observar definiçôes distintas de estilos musicais, é possível notar que textos incluídos sob a designação genérica de musica poetica encerram em si diferenças significativas.

No que diz respeito à matéria tratada, embora a musica poetica trate da arte da composição musical, é possível observar que obras seiscentistas se atêm, de modo geral, ao contraponto, enquanto textos setecentistas, como Mattheson, descrevem a prática baseada no baixo-continuo. Além disto, o público das obras seiscentistas, geralmente escritas em latim, é o de jovens estudantes das escolas latinas do mundo reformado. Mattheson, de modo diverso, destina seu livro ao galant-homme, enquanto Forkel escreve para o público universitário.

Estas diferenças acabam por gerar visões distintas, no que diz respeito à transposição de preceitos poético-retóricos para o âmbito musical. Desta forma, sob a ideia de gêneros e estilos musicais entendem-se, em tratados seiscentistas e setecentistas, classificações diversas.

A classificação mais antiga, segundo o gênero melódico e a espécie de contraponto utilizada, parece ter pouca influência na construção da relação entre música e retórica.

A segunda subdivisão, que opõe os estilos antigo (polifônico) e moderno (monódico), refere-se inicialmente à ênfase no contraponto (mais próxima do quadrivium) ou na representação do texto (vinculada ao trivium). Ela é retomada por Mattheson, que liga a polifonia ao estilo sacro e a monodia, ao teatral. Para Forkel, diferentemente, a cisão entre polifonia e monodia não indica o tipo de concepção musical nem a circunstância de lugar, mas o número de oradores envolvidos 
no discurso: a polifonia emula vozes de um grupo de pessoas, enquanto a monodia representa um monólogo. Esse afastamento da visão matemática em prol de uma ligação total com a linguagem, fundamentada em uma origem comum a ambas as artes (a emoção), parece ser o resultado de um processo já perceptível em Mattheson, mas que só se concretiza definitivamente no fim do séc. XVIII, em autores como Forkel. Isto permite a este último entender a música legitimamente como discurso, independente da presença um texto que a qualifique ou da técnica de escrita.

Considerando a importância de Cícero nas leituras cortesãs e escolares fortemente influenciadas pelo humanismo, é possível enxergar a concepção de estilo impresso, ou seja, aquele baseado na imitação de maneiras de compor de autores diversos, como uma transposição musical de questóes retóricas envolvendo a imitação de autoridades. É interessante notar que a discussão referente aos estilos nacionais, que toma enorme espaço em discussões seiscentistas e setecentistas, de Kircher a Mattheson, passa ao largo da obra de Forkel.

Vimos que a quarta e a quinta divisão de gêneros, segundo a ocasião e segundo a matéria tratada, também constituem transposições dos gêneros de causas (judicial, deliberativo, demonstrativo) e de matérias (alta, média e baixa) da retórica clássica. Vale lembrar que Mattheson subordina a matéria à ocasião, como também fazem Cícero e Quintiliano. Esta vinculação evidencia a preocupação humanista de autores da musica poética em aproximar música e retórica.

Para autores do séc. XVII, os gêneros instrumentais, por não contarem com a palavra, são claramente inferiores aos vocais. Mattheson confere à música instrumental um poder mais definido de expressão, o que permite considerar a música instrumental como "linguagem dos sons". Para Forkel, esta hierarquia deixa de ser relevante para discussão. Para ele, toda música, qualquer que seja sua técnica compositiva ou veículo de expressão, constitui uma linguagem, independente da presença da palavra.

Na última divisão, segundo os subgêneros musicais, podemos notar que a música instrumental, inicialmente concebida como um tipo de desproporção fantástica (Kircher), passa a ser legitimada na obra de Mattheson, com a inclusão do estilo instrumental, propriamente dito. Na divisão de Forkel, a fina- 
lidade e a disposição das peças definem vários gêneros, vocais e instrumentais, que não têm nenhum tipo de primazia uns sobre os outros, guardando em comum a apenas o fato de expressarem, todos, a mesma linguagem das emoções.

Assim, para autores do fim do século XVIII, como Forkel, a presença do texto deixa de ser um critério relevante para a distinção dos estilos. Para eles, toda música constitui uma linguagem. A posição que Forkel atribui, na classificação em subgêneros, à música instrumental, só é possível mediante essas modificações sutis, que permitem a ele descrevê-la como uma linguagem que representa emoções específicas do autor (e por isso, dispensam uma codificação verbal). É interessante notar que essa representação, embora individual, não deixa de ter como finalidade principal a instrução, deleite e comoção do ouvinte, pois de outro modo, a música não estaria cumprindo sua função como arte.

\section{REFERÊNCIAS BIBLIOGRÁFICAS}

ANÔNIMO. Retórica a Herênio. Trad. Angélica Chiapetta. São Paulo: Hedra, 2005

DAMMANN, ROLF. Der Musikbegriff im Deutschen Barock. Laaber: Laaber Verlag, 1995

FORKEL, Johann Nikolaus. Allgemeine Geschichte der Musik (Leipzig, 1788-1802). Laaber: Laaber Verlag, 2005

KIRCHER, Athanasius. Musurgia Universalis sive Ars magna Consoni et Dissoni (Roma, 1650). Hildesheim: Georg Olms, 1999.

KIRNBERGER, Johann Philipp. Die Kunst des reinen Satzes in der Musik (Berlin, 1771-1779). Laaber: Laaber Verlag, 1987

MATTHESON, Der Vollkommene Capellmeister (Hamburgo, 1739). Kassel: Bärenreiter, 1991

MONTEVERDI, Claudio. Madrigali Guerrieri e Amorosi (Veneza, 1638). Wien: Universal, 1990 
PAOLIELLO, Noara. Os Concertouvertures de Georg Philipp Telemann: um estudo dos Gostos Reunidos segundo as preceptivas setecentistas de Estilo e Gosto. Dissertação: ECA-USP, 2011

SCACCHI, Marco. Breve Discorso sopra la musica moderna (Varsóvia, 1649). In: PALISCA, Claude. Studies in History of Italian Music Theory. Oxford: Clarendon, 1994, p. 88-145

QUINTILIANO. Institutio Oratoria . Trad. H. E. Butler. London: Harvard University Press, 1936 (Loeb Classical Library). 